\title{
COVID-19 IN ESTONIA. RESTRICTIONS AND POPULATION'S COPING WITH THEM
}

\author{
Ene-Margit Titit ${ }^{1}$, Marianna Makarova ${ }^{2}$ \\ ${ }^{1}$ Statistics Estonia; University of Tartu, Tartu, Estonia \\ ${ }^{2}$ Government Office of the Republic of Estonia, Tallinn, Estonia
}

\begin{abstract}
The article is based on a selection of data commissioned by the Government Office of the Republic of Estonia and received during 10 weeks from weekly surveys (COVID-THEMATIC SURVEY) conducted by Turu-uuringute AS, a market research company.

The study began on 17 March and lasted for 10 weeks to 21 May. On three days of every week, about 2,000 Estonian residents aged 15 and over were interviewed. The respondents were randomly selected and represented the entire population of Estonia in terms of gender, age, ethnicity and social affiliation.
\end{abstract}

The time series on the assessment of virus infections, hospital and intensive care (mechanical ventilation) and COVID deaths, compiled on the basis of data published by the Health Board, was also used as background information.

The first three rounds took place during the period of increasing morbidity, the following four rounds (4-7) during the study period when the morbidity situation remained more or less stable, and all the established restrictions also applied. The last stage, rounds $8-10$, took place at a time when morbidity was declining and restrictions were gradually eased.

The survey revealed that Estonia was not ready for the crisis - just like most of the world's countries. The crisis tested, on the one hand, the government's ability to make difficult decisions and make significant use of the brain potential of the country's research community, and, on the other hand, the people's reasonableness, stress tolerance and ability to comply with rather awkward restrictions. It follows from the present analysis that all the restrictions were opposed by those who did not believe in their appropriateness. However, compared to the total population, their number was small, and, 
therefore, the restrictions in Estonia were maintained without sanctions and no contradictions arose, let alone unrest.

The open action of the Crisis Committee was very important: the number of new infections, the number of patients in need of hospital treatment and mechanical ventilation, as well as the number of deaths, were reported daily at both the government press conference and in the media. The survey showed that there were very few people in the country who thought they did not know everything they needed about the crisis. The fact that people remained rather cautious in their assessments even after the end of the emergency situation adds to the hope of coping with the virus in the future - should a second wave or any other threat come.

Keywords: Covid-19; quarantine; representative sample; interview; attitude

\section{THE CRISIS SITUATION AND THE RESTRICTIONS IMPOSED}

In total, 1979 SARS-CoV-2 cases and 63 COVID-19 deaths were recorded In Estonia from 26 February to 19 June 2020.

The first COVID-cases were identified at the beginning of March among people returning from skiing-trips in Italy and Austria. Soon, however, it became evident that the illness was spreading in Estonia too. Estonian government declared the emergency situation in the state on 13 March when the number of cases per day was already more than 20 .

From 13 March, public gatherings, cinema sessions, concerts, conferences and sporting events were banned. Visits to hospitals, care facilities and prisons were forbidden. The shipping line to Stockholm was closed, and incoming travellers were asked on the borders about their health. On 14 March, the number of infected people was already 68. On this day, all entertainment events were banned, and traffic between the mainland and the islands of Saaremaa, Muhumaa, Hiiumaa and the small islands of Estonia was closed. On 16 March, studies in hobby schools were suspended, schools and higher education institutions switched to distance learning.

On 17 March, border control was established, and everyone arriving in Estonia was subject to a 14-day mandatory quarantine. As meetings and parties at public places turned out to be particularly dangerous in terms of the spread of the infection, night alcohol sales in taverns, restaurants and bars were banned on 18 March.

On March 25, the first CoVID-19 victim died in Estonia. The $2+2$ rule was introduced on that day. Although it was an order and information posters were 
placed in public places, law enforcement officers mostly confined themselves to admonishing the offenders.

On 26 March, the daily number of patients exceeded 100 for the first time.

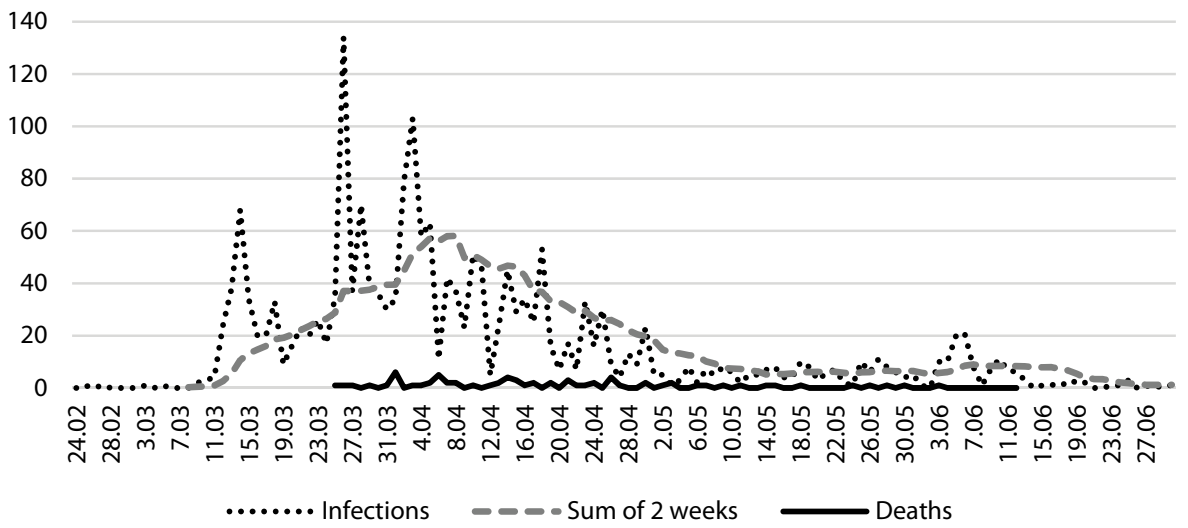

Figure 1. Morbidity and mortality by day and sum of cases of infection per 100,000 population over two weeks

Shopping malls were closed on 27 March; only shops for food and basic necessities remained open. On $28 \mathrm{March}$, an order came into force according to which those infected with the coronavirus and their family members had to stay at home. On 29 March, stricter movement restrictions were imposed in the islands of Saaremaa and Muhumaa where the proportion of infections was the highest. On 3 April, movement restrictions in nursing homes came into force.

The virus was predicted to peak in mid-April, but, in fact, the daily number of cases began to decline as early as at the beginning of April. The last day when the number of new cases exceeded one hundred was 3 April, and, from 8 April, the sum of 100,000 infections per capita detected in two weeks also began to decline (dashed line in Figure 1).

By 7 April, it had dropped below 25, and the number has not been exceeded since then.

Throughout April (until the end of the initially declared emergency), the restrictions remained, nothing significant was changed, but at the end of April, restrictions began to be eased. Movement restrictions in Saaremaa and Muhumaa were partly abolished on 28 April. Although the state of emergency was extended to 17 May, restrictions were gradually eased.

In general, the restrictions imposed in Estonia were partly strict (e.g. border controls, closures of schools, theatres and sports facilities, and bans on crowded events), partly advisable rather, such as staying at home as much as possible, 
and the $2+2$ rule of social distancing, which was not checked everywhere. Full traffic control was not introduced in the cities, but the streets were much emptier than usual. Wearing masks was not mandatory but only recommendable at some places, e.g. in public transport. Many of the inhabitants procured masks (there was a shortage of them in pharmacies in March), but wearing them was not very popular.

April as a whole was the time of the most severe restrictions. Obviously, the restrictions worked: at the beginning of May morbidity stabilised at a relatively low level. From 12 May, the total morbidity of two weeks per 100,000 inhabitants was less than seven and remained at that level until mid-August.

\section{STUDY}

Our study began on 17 March and lasted for ten weeks (until 21 May). About 2000 Estonian residents were interviewed on three days every week, (Monday Tuesday and Wednesday). A random sample representative of the population of Estonia (aged 18 years and more) by gender, age, ethnicity and social background was used. The purpose of the survey was to find the population's attitudes towards restrictions, information about the corona crisis, concerns and fears, and people's ability to deal with the crisis situation. The survey had some fixed blocks, e.g. the respondents' information channels that were asked each time. In all rounds of the survey, the respondents were also asked to assess the feasibility of government measures. Three times, the study took place during a period of increasing morbidity; during the four following periods, morbidity remained more or less stable, and all restrictions also applied. The final stage (rounds 8-10) occurred at a time when morbidity decreased, and restrictions were gradually relieved.

\section{AWARENESS OF THE POPULATION OF ESTONIA OF THE DANGER AT THE BEGINNING OF THE CRISIS}

In the first and second rounds of research on 17-19 and on 24-26 March, the question "How serious do you think the situation caused by the coronavirus in Estonia is?" was asked. The response options were "very serious / rather serious / rather not serious / not serious at all / can't answer". The distribution of answers is shown in Figure 2. 


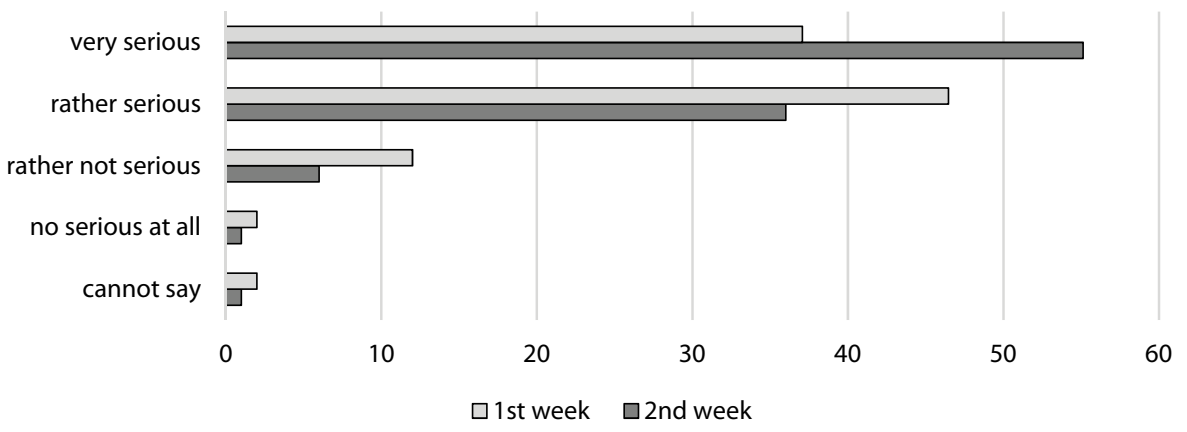

Figure 2. Assessment of the severity of the coronavirus situation

During the intervening week, the infection in Estonia reached close to the peak level, and the respondents' assessment of the gravity of the situation changed. If in the first round of the survey the most frequent answer was "rather serious" (more than $40 \%$ of the respondents), during the second round of responses, the situation was considered very serious by more than half of the respondents. This question was no longer asked in the subsequent rounds.

\section{INFORMATION}

The first three rounds of the survey examined how well the respondents were aware of the circumstances of the corona crisis. The question asked was "How well are you aware of what you personally could do in the present situation to reduce the risks associated with the coronavirus?" The distribution of responses is shown in Figure 3. As the third round of surveys revealed that the level of general awareness was over $98 \%$, this question was not asked in the subsequent rounds.

However, the information channels used by the respondents were still examined, asking them to select the three most frequently used ones from among 16. Throughout the study, the respondents reported using an average of 2.7-2.8 channels; the most preferred ones were the Estonian internet portals, ETV (Estonian Television) programs, radio and err.ee (portal of Estonian Public Broadcasting). Social media was also at a relatively high place; on the other hand, friends, acquaintances and relatives as well as newspapers lagged behind. ETV+ (the Russian-language channel of Estonian Television) was more popular than Russian TV channels and PBK (a Russian-language TV channel produced for the Baltic countries). From here it follows that, during the crisis, the population of Estonia followed the common information field, created in 
Estonia. There were very few people who admitted that they were not interested in the topic - in average $1.3 \%$ of the population; this number increased slightly during the study.

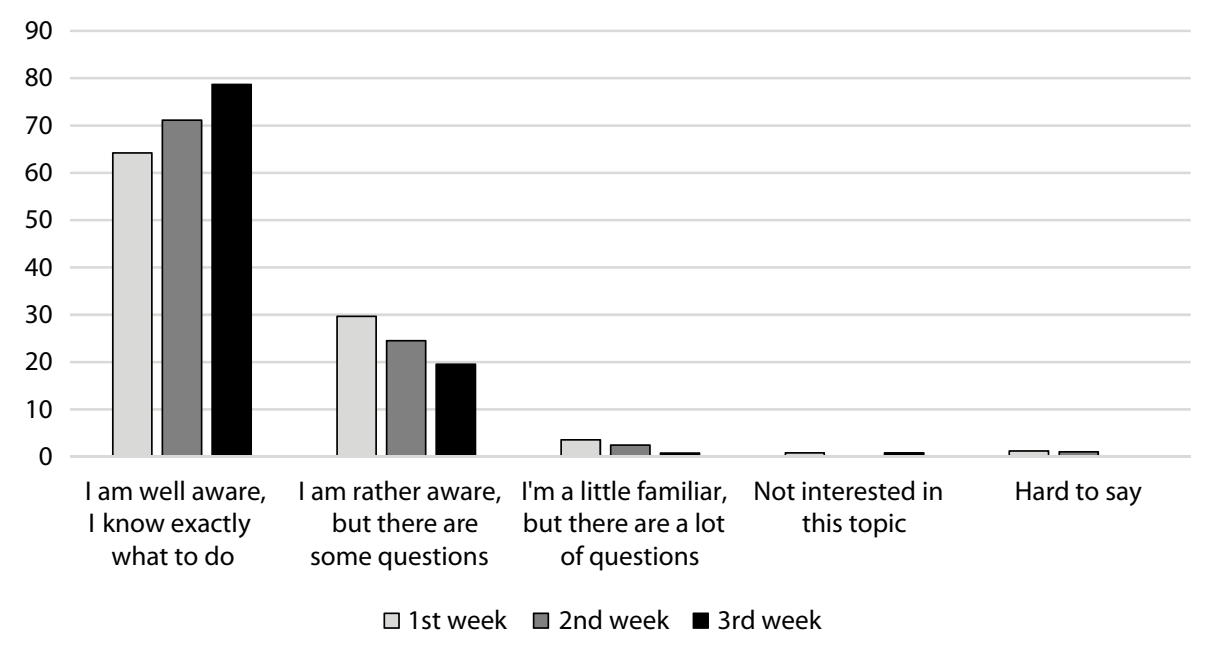

Figure 3. Awareness of the population during the first three weeks of the study

\section{RESPONDENTS' ASSESSMENT OF THE GOVERNMENT MEASURES}

In the first round (17-19 March), when the state of emergency had lasted for less than a week, but most of the significant restrictions had entered into force, three questions were asked about the measures taken. The respondents were asked to either confirm or deny the following statements: "I think these restrictions have been overstated" ( $4.8 \%$ in the affirmative); "I think these measures do not help anyway" ( $2.3 \%$ in the affirmative); "I think the negative impact of the measures on the economy is greater than the impact of the virus itself" (6.5\% in the affirmative).

From the second round of the survey, the respondents were asked: "How do you assess the relevance of the measures taken so far? Do you think they should be changed? " and the following answer options were put forward: the measures should be made "definitely tougher / rather tougher / the measures are appropriate and relevant, there is no need for change at present / rather more lenient / definitely more lenient / cannot say". Leaving aside the answer "cannot say" (chosen by an average of $1.8 \%$ of respondents), we get a picture of the change in attitudes, shown in Figure 4. 


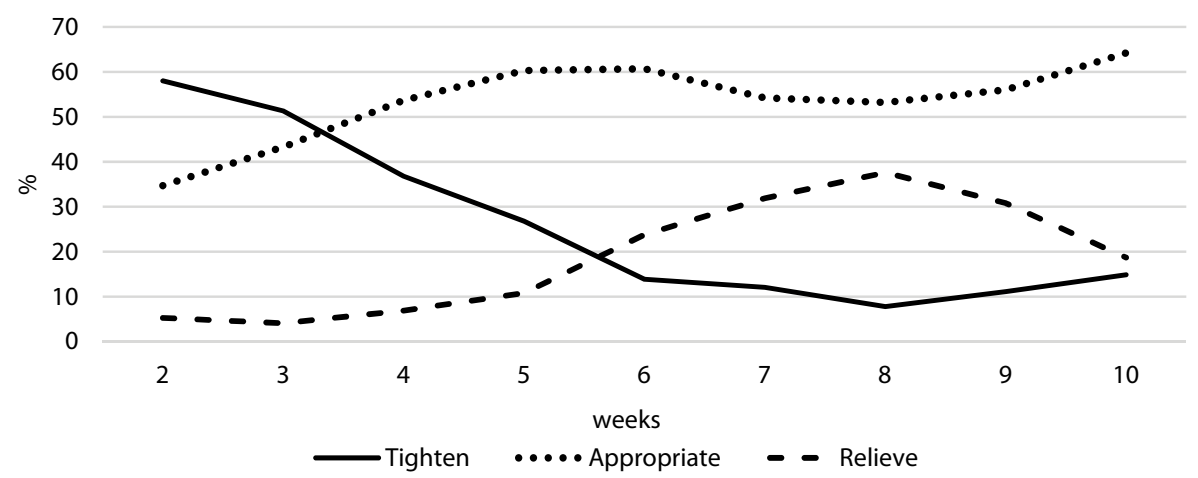

Figure 4. Respondents' assessment of the measures

\section{DYNAMICS IN THE SHARE OF "TIGHTENERS" AND “MITIGATORS"}

During the first polls, a large number of respondents were in favour of tightening the measures, but this attitude declined steadily until it reached $8 \%$ in the 8th week of the survey (5-7 May). At the time when a lot of restrictions had been cancelled, the proportion of respondents who considered it appropriate to tighten the restrictions rose to $15 \%$ again. In the first weeks of the survey, only a few $-4-5 \%$ of the respondents - considered the easing of measures justified, but their number increased with the addition of restrictions. The number of those who wanted relief increased relatively quickly from week 4 to week 8 . This was the time when morbidity had gradually decreased, but many of the restrictions remained valid.

The proportion of respondents who considered the measures appropriate increased from $35 \%$ at baseline to $65 \%$ at the end of the study. While initially respondents wishing to step up the measures were predominant, between survey weeks 3 and 4, in early April, the set was in place, the attitudes were balanced, and support for the measures introduced increased steadily until it exceeded $60 \%$ in the $5^{\text {th }}$ and $6^{\text {th }}$ weeks (the second half of April), when, contrary to initial fears, there was no sharp increase in infection but a gradual shrink instead. As a result, satisfaction with the measures slightly decreased again in weeks 7 and 8 (late April and early May), expressing the pressure to ease the constraints. In the last weeks of the study, when a significant part of the restrictions had been relaxed, satisfaction with the measures increased to around two thirds of respondents. The number of respondents who wanted the measures to be tightened or relaxed was also relatively well balanced between 15 and 20\% 


\section{WHO WERE THOSE WHO WANTED TO EASE THE MEASURES?}

Of course, the group of "mitigators" in the population could not be the same in all the rounds of interviews, but it is still interesting which features characterise the people belonging to this group. It turns out that these characteristics are not so easy to find. These respondents were slightly younger than average, i.e. there were somewhat fewer elderly people among them, but the difference was not great. There were slightly more persons with higher education and predominantly people engaged in the workforce, including slightly more managers than average. The relationship between Estonians and other ethnicities as well as the relationship between men and women was the same as in the general population. The mitigators did not stand out among the rest of the population by their different behaviour.

\section{POSSIBLE ADDITIONAL MEASURES}

At some stages of the study, people were asked about their views on possible additional restrictions and limitations. In the third week (31 March to 2 April), at the peak of morbidity when there was still a growth trend, respondents were asked about their views on four possible additional measures. These were: "Close all shops except food and convenience stores" (69\% agreed); "Close all restaurants, bars, cafes and other catering establishments" (75\% agreed); "Allow only people of certain occupations to work, e.g. doctors, shop assistants, police officers, food industry workers, plumbers, energy workers, etc." (58\% agreed); "Restrict entry to and exit from Harju County similarly to the Estonian islands" (30\% agreed). In the fourth week (7-9 April), the question on public transport was asked: "Would you agree to restrict the use of public transport so that only half of the seats on a bus / tram / train could be used?" Again, 75\% of respondents agreed to such a measure. These figures show that concerns about the spread of the virus were widespread in the society. Possible addition of restrictions was supported but still selectively: although, for example, threequarters of the population supported the closure of restaurants, the closure of Harju County (analogously to the option implemented in Finland) was not considered appropriate by most respondents. 


\section{BEHAVIOURAL SELF-ASSESSMENT}

Questions about compliance with the rules were asked in all the rounds of the study. Although the questions varied slightly during the study, some generalizations could be made. In the first three weeks the following question was asked: "Everyone can do a lot to hinder the spread of the coronavirus (for example, avoid contacts with other people, stay at home, wash one's hands, etc.). Which of the following descriptions best describes your behaviour?" The answers were: "I do everything I can - I stay at home, wash my hands, etc.) / I do a lot, but if I worked hard, I could do more / I only do something if I remember, or it is convenient, otherwise I live a normal life / I do nothing special, I live a normal life." From the fourth week, the answer variants to the same question were as follows: "I remember and follow all the official instructions whenever I can (if possible, I stay at home, I follow the $2+2$ rule when moving outside) / I follow most instructions and partly change my behaviour / I follow some rules (if they do not require special effort) / I do nothing special, I live a normal life." Although the wording has changed, it is possible to observe the persistence or change of attitude during the observation series (see Figure 5). The predominant attitude was to follow all rules, starting from $60 \%$ in the first week of the study and rising to over $80 \%$ by the fourth week, then gradually declining and falling to $56 \%$ by the end of the period. The distribution of this characteristic is well described $\left(\mathrm{R}^{2}=0.93\right)$ by a parabola with its vertex between study weeks 4 and 5 (i.e., April 10-12) when morbidity in Estonia was at its highest level. The number of people who did not follow the rules but continued their old habits was relatively small. Their share was almost $7 \%$ at the beginning of the survey, decreased to $2 \%$ by weeks 3 and 4 and increased to over $5 \%$ by the end of the study.

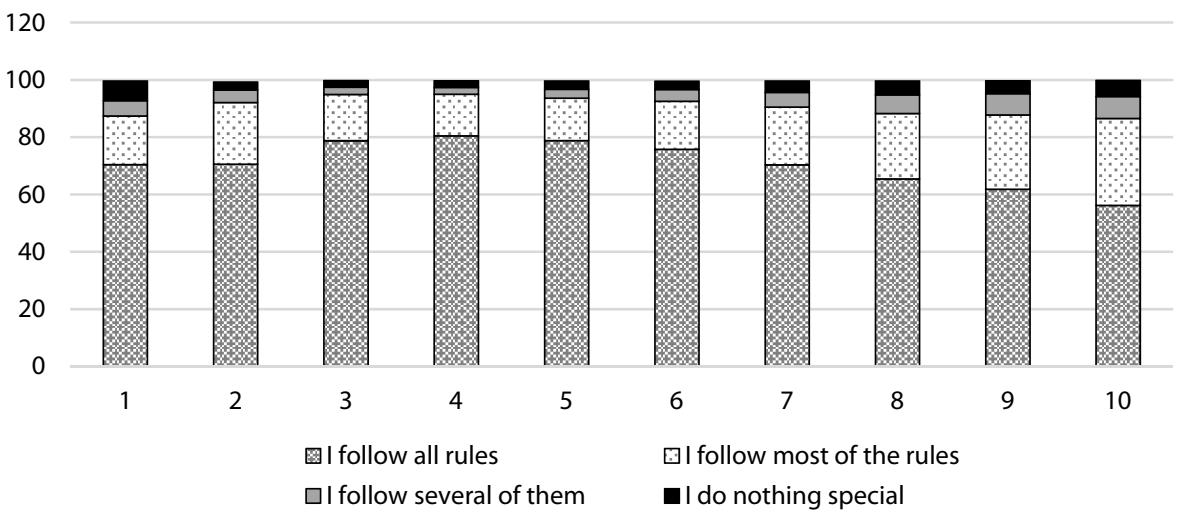

Figure 5. Following the rules fixed by the government. 
Men with such a behavioural pattern were mostly slightly younger than average, with a lower than average level of education. Quite a large number of them were skilled workers in "manly" occupations, and there were slightly fewer ethnic Estonians among them than the average.

\section{HYGIENE MEASURES}

In the last three weeks of polls (5-7, 12-14 and 19-21 May), respondents were provided with a list of personal hygiene measures used to control the virus in order to find the intensity of their use. The results are shown in Figure 6.

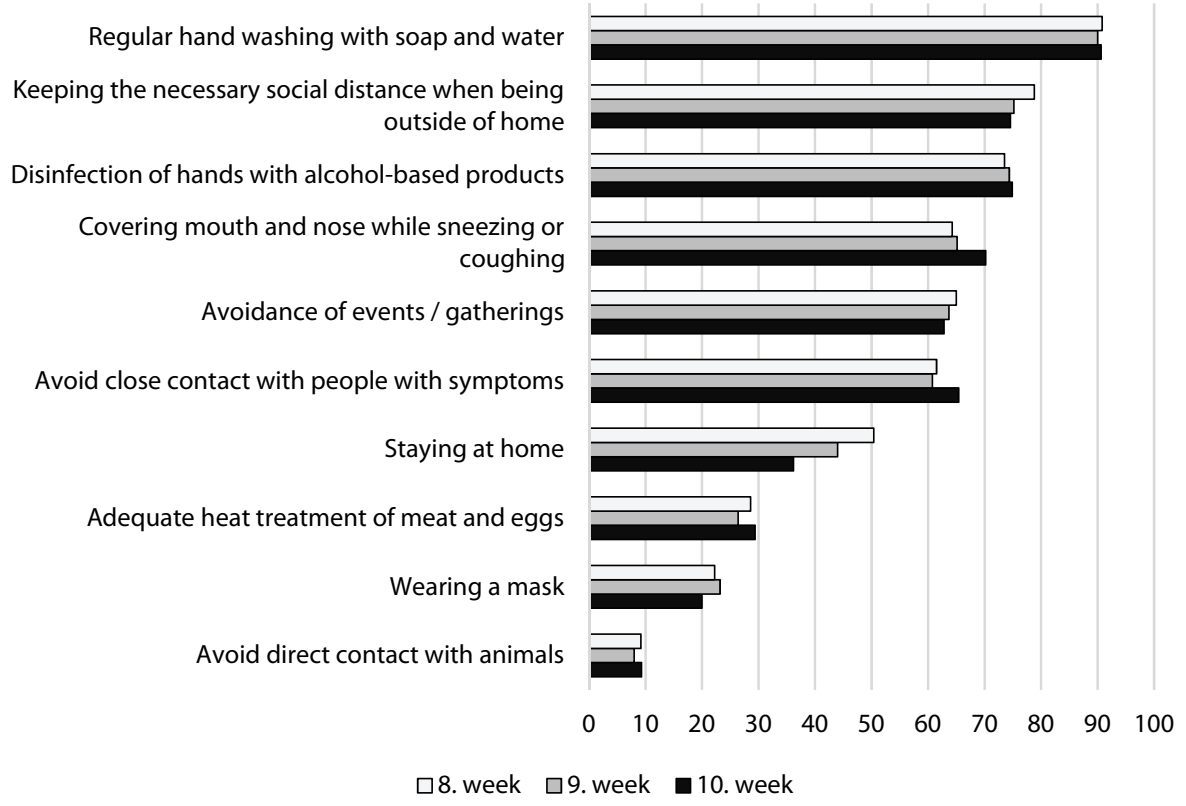

Figure 6. Using hygiene measures in the $8^{\text {th }}-10^{\text {th }}$ weeks of study

It turned out that $90 \%$ of the respondents adopted regular hand washing (or continued this habit), but, for example, while sneezing, less than $70 \%$ of respondents covered their faces. As the restrictions were eased during this period, the share of people staying at home decreased from $50 \%$ to $35 \%$. Other unforced measures were less popular. 


\section{MASKS}

From the first round of interviews, it was examined (with some intervals) how many respondents were interested in having a virus test, and how many were concerned about obtaining protective equipment. Both indicators were relatively stable, fluctuating between 20 and $25 \%$, and there was no definite trend. Respondents' attitudes towards masks were examined in more detail in the 6th round of the survey (April 21-23), which took place during the peak period of the virus outbreak. Because health experts did not agree on the protective effect of masks, masks were difficult to obtain and their quality questionable, the attitude of the population towards wearing masks was also ambivalent. About 15\% of respondents declared that they would not agree to wear a mask at any places.

To protect yourself from possible infection

To prevent infecting other people

To enable opeingn and keeping open shopping malls and catering establishments

Just in case

To enable opening sports and cultural institutions

To enble opening playgrounds and children's facilities

I just like the idea of wearing a mask

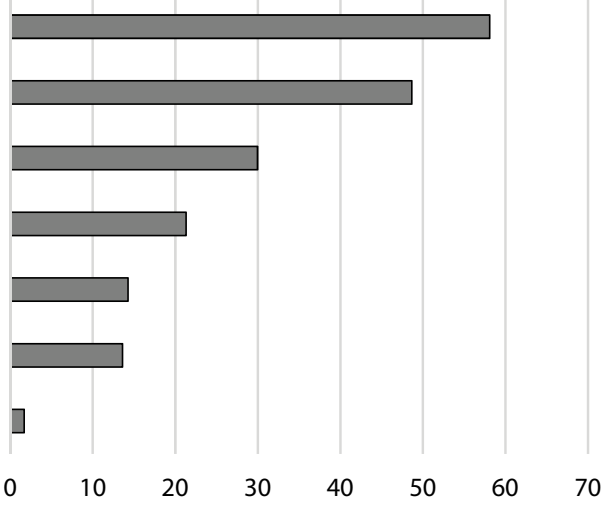

Figure 7. Assessment of the objectives of wearing a mask in the 6th week of the survey

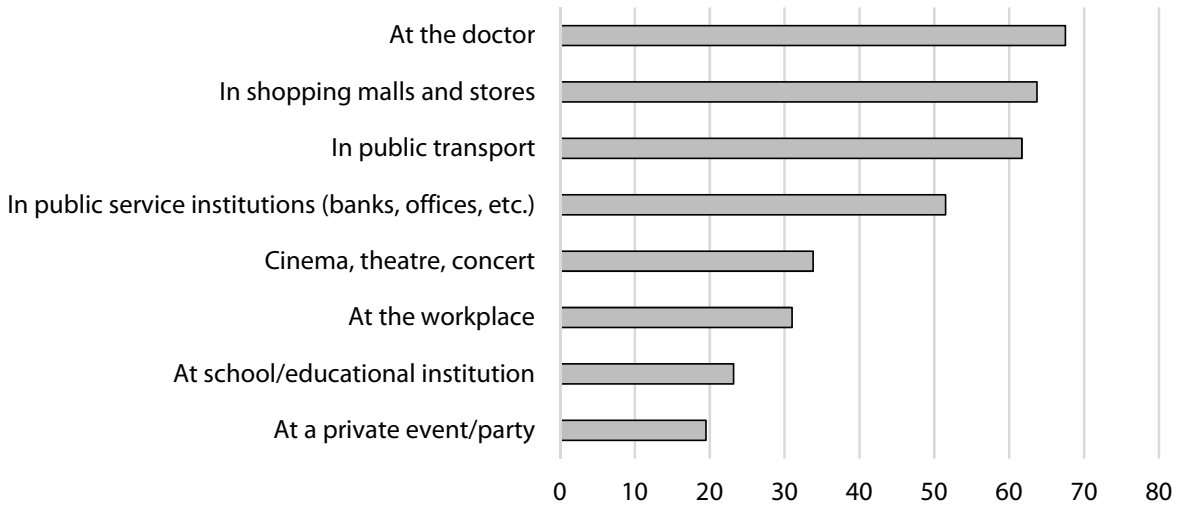

Figure 8. Where to wear the mask? The $7^{\text {th }}$ week of the study 
In the 7th round (April 28-30), the study on masks continued: it was asked at which places one agreed to wear a mask. More than a quarter of the respondents turned out to be particularly reluctant to wear a mask: "I would not like wearing a mask to be mandatory, but I would voluntarily agree to wear it" (27\%). One sixth of the respondents questioned the effectiveness of the mask: "I do not think that wearing a mask will protect my health." During both rounds of interviews, $12-13 \%$ of respondents refused to wear a mask.

\section{ELECTRONIC MONITORING}

For the first time, the possibility of electronic monitoring to verify compliance with quarantine requirements was addressed in the 3rd week of the survey (31 March to 2 April). It turned out that a large proportion of respondents would agree to it. The possibility of electronic tracking was discussed in more detail in weeks 7 and 8 of the survey (28-30 April and 5-7 May). In the seventh week, an explanation was provided with the question: "Work is in progress on a mobile application by which everyone could know if he or she has been exposed to the coronavirus in such a way that the infection could be transmitted. What would be the main reasons why you would agree to use such a mobile application?" The same question was asked in the 8th round and the distribution of responses is shown in Figure 9.

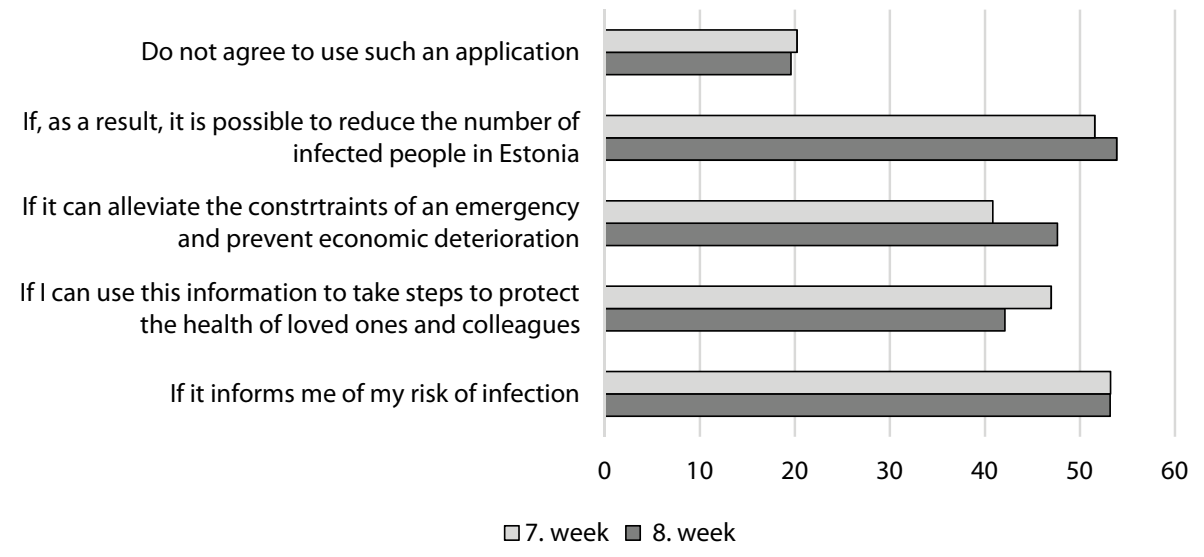

Figure 9. Consent to use a mobile application that detects infection.

Compared to the first time, the respondents' attitudes had become more critical. About half of the respondents agreed to use such an application under certain conditions and for specific purposes, but there were concerns about the 
protection of personal data. A large majority of respondents agreed to use the application only if it does not make it possible to detect a person.

\section{ATTITUDES TOWARDS RESTRICTIONS}

However, it would be erroneous to conclude that all the respondents agreed to the restrictions and did not see any problems in implementing them. In the first round of the survey, almost a third of the respondents stated that they agreed to the statement "I am concerned that, due to the quarantine, I cannot be together my relatives living abroad." This question was not repeated later, but in the $5^{\text {th }}$ round (April 14-16, just before spring school holidays), families with children were asked if they planned to visit grandparents and/or relatives living away. It turned out that less than $1 \%$ of respondents had such an intention. From the third round of the survey, people were asked about their attitudes to the statement "I'm tired of being at home, life needs to go on." As expected, boredom increased over time almost linearly, but reached only $12 \%$ by the end of the study. There were various groups of people among the respondents who were dissatisfied with the restrictions - those who did not implement any hygiene measures, those who still visited crowded places, who stated that they were not afraid of infection, and also those who were sceptical about the restrictions. Yet, such people were always in the minority. Most of them were people with risky attitudes or risky behaviour, with a lower than average level of education and younger than average men who were also much less interested in information about the coronavirus. They were also among those who thought that the measures should be relaxed during the emergency. Among the proponents of mitigation however, there were also respondents with a higher level of education, social status and income. The proportion of proponents of easing restrictions rose to the maximum level - 40\% - in week 8 (5-7 May), i.e. just before the government started to lift restrictions. In the last weeks of the study, when the deadlines for ending the restrictions were known, and some of them had already expired, the number of respondents who emphasised the need to ease restrictions decreased.

\section{RESPONDENTS' ATTITUDE AT THE END OF THE EMERGENCY}

The last, tenth week of surveys (19-21 May) took place after the end of the state of emergency when the initial mitigation measures were published (see e.g. the newspaper Postimees, 16 May 2020). In this round, a question on the 
assessment of the situation was asked: "Which of the following statements do you think best describes the current coronavirus situation in Estonia?" The predominant answer (about 60\%) was: “... must remain vigilant and comply with safety requirements." Another question examined the respondents' assessment of the solution to the crisis in Estonia: "The corona crisis has affected the whole world. Each country has chosen its approach to resolving the situation, and the results have been mixed. How satisfied are you with how the situation has been resolved in Estonia so far?" The distribution of the answer options is shown in Figure 10. The assessment of the situation was characterised by cautious optimism, as this time the respondents were overwhelmingly satisfied with the resolution strategy.

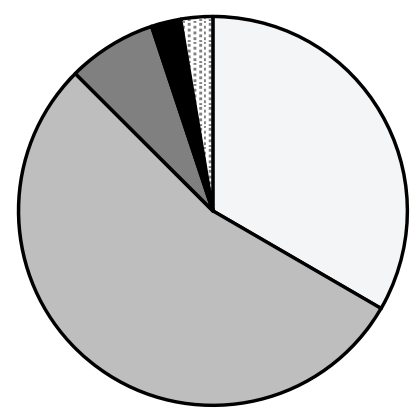

口 believe that the situation has so far been resolved in the best possible way

I think some things could have been done better

口I think a lot could have been done better

I think that the wrong approach was chosen in Estonia

田hard to say

Figure 10. Respondents' satisfaction with solving the corona crisis in Estonia

\section{CRISIS AS A LESSON - A SHORT CONCLUSION}

Like most countries in the world, Estonia was not ready for a crisis. There had been no pandemic in the Western world for over a hundred years, the dangers were seen in terrorism, cybercrime and political instability rather than in natural disasters. On the one hand, the crisis tested the government's ability to take difficult decisions and harness the brain potential of the national research community, on the other hand, the reasonableness, stress tolerance and ability of the people to reconcile at times with rather inconvenient restrictions. The ten-week study that formed the basis of this analysis shows that there were opponents of all restrictions who did not believe in their appropriateness and acted at their own discretion. But compared to the total population, there were few of them; the restrictions were generally complied with in Estonia without the need for severe sanctions; no contradictions, let alone unrest arose. 
The first wave of the crisis was managed relatively well in Estonia. The main factor here was the sensible behaviour of the entire population. An advanced digital culture also helped, allowing remote work and many operations to be performed without direct communication. Certainly, the relatively sparse population of Estonia was also helpful in the situation that arose.

\section{Address for correspondence:}

Ene-Margit Tiit

Institute of Mathematics and Statistics

University of Tartu

Narva 18, 50409, Tartu, Estonia

E-mail: ene.tiit@ut.ee 